4 Jacobsen D, Frederichsen PS, Knutsen KM, Sorum Y, Talseth T, Odegaard OR. A prospective study of 1212 cases of acute poisoning: general epidemiology. Hum Toxicol 1984;3:93-106.

5 Hawton K, Blackstock E. Deliberate self-poisoning: implications for psychotropic drug prescribing in general practice. $\mathcal{I} R$ Coll Gen Pract 1977;27:560-3.

6 Ananth J, Ghadirian AM. Drug-induced mood disorders. Int Pharmacopsychiatry 1980;15:59-73.

7 Prescott LF. Safety of the benzodiazepines. In: Costa E, ed. The benzodiazepines: from molecular biology to clinical practice. New York: Raven Press, 1983:253-65.

8 Baker PM, Bartholomeusz DB, Siskind M, Whitlock FA. Drug-induced depression and attempted suicide. Med J Aust 1977;ii:322-4.

9 Oswald I. The why and how of hypnotic drugs. Br Med $\mathcal{F} 1979 ; \mathrm{i}: 1167-8$

10 Hall RCW, Joffe JR. Aberrant response to diazepam: a new syndrome. Am $\mathcal{J}$ Psychiatn 1972;129:738-42.

11 Ryan HF, Merrill FB, Scott GE, Krebs R, Thompson BL. Increase in suicidal thoughts and tendencies: association with diazepam therapy. $\mathcal{F A M A} 1968 ; 203: 1137-9$

12 Johnson DAW. Drug-induced psychiatric disorders. Drugs 1981;22:57-69.

13 Alarcon R de, Carney MWP. Severe depressive mood changes following slow-release intramuscular fluphenazine injection. $\mathrm{Br}$ Med $\mathcal{F} 1969$;iii:564-7.

14 Starkey IR, Lawson AAH. Psychiatric aspects of acute poisoning with tricyclic and related antidepressants-a ten-year review. Scott Med f 1980;25:303-8.
15 Skegg K, Skegg DCG, Richards SM. Incidence of self poisoning in patients prescribed psychotropic drugs. Br Med f 1983;286:841-3.

16 Jones DR. A follow-up of self-poisoned patients. $\mathcal{F}$ R Coll Gen Pract 1977;27:717-9.

17 Khan A, Hornblow AR, Walshe JWB. Benzodiazepine dependence: a general practice survev. NZ Med F 1981;94:19-21.

18 Petursson $\mathrm{H}$, Lader $\mathrm{MH}$. Withdrawal from long-term benzodiazepine treatment. $\mathrm{Br}$ Med $\mathcal{f}$ $1981 ; 283: 643-5$.

19 Hopkins DR, Sethi KBS, Mucklow JC. Benzodiazepine withdrawal in general practice $\mathcal{I} R$ Coll

20 Owen RT, Tyrer P. Benzodiazepine dependence. A review of the evidence. Drugs 1983;25:385-98.

21 Ashton H. Benzodiazepine withdrawal: an unfinished story. Br Med f 1984;288:1135-40.

22 Anonymous. Tranquillisers causing aggression [Editorial]. Br Med f 1975;i:113-4.

23 Brewer C, Farmer H. Self poisoning in 1984: a prediction that didn't come true. Br Med $\mathcal{J}$ 1985;290:391.

24 Kessel N. The respectability of self-poisoning and the fashion of survival. $\mathcal{J}$ Psychosom Res 1966;10:29-36.

\title{
Impact of whooping cough on patients and their families
}

\author{
I D A JOHNSTON, M HILL, H R ANDERSON, H P LAMBERT
}

\begin{abstract}
The effects of whooping cough were studied in 21 children admitted to hospital with the disease and in their families. The illness caused considerable distress to both child and family. Parents suffered especially from fears for the life and health of their child and from serious loss of sleep. Two months after admission the child's behaviour was still disturbed, but in most cases the rest of the family had returned to normal. There was much misunderstanding and misinformation about whooping cough among both parents and doctors.
\end{abstract}

\section{Introduction}

The controversy about vaccination against whooping cough has led to renewed interest in the disease, and much information has been obtained about its severity and complications in recent epidemics. ${ }^{1-4}$ Few objective data are available, however, on the impact of the illness on the child's family. This study describes the effects of whooping cough on 21 children admitted to hospital and their families.

\section{Patients and methods}

Eighteen of the 21 children with whooping cough studied were admitted consecutively to this hospital, and three were admitted to two nearby hospitals over the same period. All children had an illness satisfying our diagnostic criteria for whooping cough. ${ }^{5}$ The mothers of these children were interviewed on two occasions. The first interview took place in the ward within six days of the child's admission, and the second was carried out at home eight to 13 weeks after admission in 19 cases and, for operational reasons, four to five weeks after admission in the two others. The interviews

\footnotetext{
Departments of Clinical Epidemiology and Social Medicine and Communicable Diseases, St George's Hospital Medical School, London SW17

I D A JOHNSTON, MD, MRCP, clinical research fellow

M HILL, BSC, MSC, clinical psychologist

H R ANDERSON, MD, FFCM, senior lecturer in clinical epidemiology

H P LAMBERT, MD, FRCP, professor of microbial diseases

Correspondence to: Dr I D A Johnston, Medical Unit, Middlesex Hospital Medical School, London WIN 8AA.
}

consisted of structured but open ended questions providing a systematic approach without limiting the scope of information gathered. ${ }^{6}$

Maternal assessments of subjective items such as the quality of the marriage were graded on simple scales-for example, from 1 (very unhappy) to 5 (very happy). The child's behaviour was assessed by check lists graded on a scale of 1-3. Family activities were assessed by check lists of possible everyday activities of the child with its mother or father (13 point scale) or $\infty$ with its siblings (11 point scale) or of the mother and father alone (12 point scale). The positive replies on these check lists were summed to provide overall variables of family life, and the check list of the child's behaviour was similarly analysed. Social class was derived from the father's occupation where relevant and otherwise the mother's. Both interviews with each mother were carried out by the same interviewer (IJ or MH). The hospital ethical committee approved the study.

\section{Results}

The children had a median age of 9 months (range 1-67): 12 were aged under 1 year, three were aged 1 year, and six were aged 3-5 years. Fourteen mothers were married, two separated, and five single. Fourteen families were of manual social class.

The mean duration of illness was 11.7 weeks (table I). This included data on four children who were not considered by their mothers to have returned to normal health at the time of the second interview (12-19 weeks after the start of the illness). The mean time from onset to "definite improvement" was $9 \cdot 3$ weeks.

TABLE 1-Duration of illness

\begin{tabular}{lccc}
\hline & Mean (SD) & Median & Rang \\
\hline Duration of illness before admission (days) & $33 \cdot 1(24 \cdot 1)$ & 28 & $7-91$ \\
Duration of admission (days) & $10 \cdot 1(11 \cdot 1)$ & 6 & $1-46$ \\
Time from discharge until improvement (weeks) & $3 \cdot 1(2 \cdot 1)$ & 2 & $0-10$ \\
Duration of illness until improvement (weeks) & $9 \cdot 3(4 \cdot 2)$ & $8 \cdot 3$ & $3 \cdot 18$ \\
Time from discharge until better (weeks) & $5 \cdot 5(2 \cdot 8)$ & 5 & 0.11 \\
Duration of illness (weeks) & $11 \cdot 7(4 \cdot 7)$ & 10 & $4-20$ \\
\hline
\end{tabular}

Parental knowledge and anxieties-Thirteen mothers said that they had known little or nothing about whooping cough before their child's illness. Nevertheless, 16 had thought that it was probably a moderately severe or severe illness, and most seemed well informed about its possible duration. After the illness 17 mothers thought that it had been more severe than they had envisaged, and even those who had seen whooping cough on television programmes had underrated its severity. The episodes of choking, apnoea or cyanosis were the most distressing aspect of the illness for 15 mothers, and 
many commented on their feelings of helplessness at such times. In the acute stage of the illness 18 mothers thought that their child might die (table II), and about half at both interviews were worried about possible permanent chest trouble. Other worries at the second interview were the possibility of recurrence of the illness, loss of weight, whether the illness had retarded development, and whether the child was "ever going to be really well again."

TABLE II-Parental concerns about outcome

\begin{tabular}{lcc}
\hline & First interview & Second interview \\
\hline Permanent chest trouble & 11 & 11 \\
Brain damage & 6 & 0 \\
Death & 18 & 0 \\
Other & 1 & 4 \\
Nil & 1 & 9 \\
\hline
\end{tabular}

Contact with health services-The child's general practitioner first saw the child at a mean of $5 \cdot 2$ days (range 1-14) after the start of the illness. Before admission the 21 children were seen by their general practitioners on 98 occasions (mean $4 \cdot 7$, range 2-13), and in 11 cases there were also 29 telephone calls unconnected with visits to the general practitioner. Many children attended an accident and emergency department immediately before admission, but six had made such a visit on 12 other occasions during the illness (one child had made four visits to three different hospitals, another three visits to two hospitals, and another two visits to one hospital). Four children had been referred to an outpatient department, including one of those who had visited an accident and emergency department, and six had been assessed in a hospital ward without being admitted, including four of those, who had been to an accident and emergency department. Four children had been taken to the baby clinic for advice.

Despite this extensive use of services the interval between the beginning of the illness and a definite or probable diagnosis of whooping cough by a medical practitioner ranged from two to 70 days (mean 24). Nine children had been seen by a medical practitioner on more than four occasions before diagnosis. Fifteen mothers, however, had been sure of or had strongly suspected the diagnosis before it was accepted by doctors.

Effect of the illness on the child-Eighteen children had previously been considered to be healthy. Fourteen mothers thought that their child had been very distressed and exhausted by the illness, though five children, of whom three were aged 3 or more, had coped quite well. Nine mothers considered that the stay in hospital had been a definitely adverse experience for the child. The child's behaviour deteriorated considerably during the illness, with an increase in the mean score on the check list of nearly $70 \%$ $(p<0 \cdot 0001)$ (table III). By the second interview the score had decreased but was still significantly higher than that before the illness $(p=0.002): 10$ children were more attention seeking and five more naughty than before the illness, though nine were back to normal.

TABLE III-Scores for behaviour on the check list

\begin{tabular}{lccc}
\hline & $\begin{array}{c}\text { Before } \\
\text { illness }\end{array}$ & $\begin{array}{c}\text { Just before } \\
\text { admission }\end{array}$ & $\begin{array}{c}\text { At second } \\
\text { interview }\end{array}$ \\
\hline Total & 233 & 387 & 265 \\
Mean $(\mathbf{n}=21)$ & $11 \cdot 1$ & $18 \cdot 4$ & $12 \cdot 6$
\end{tabular}

Score before illness $v$ score before admission, $\mathrm{p}<0.0001$; score before illness $v$ second interview score, $p=0.002$ (paired $t$ test).

Effects on other members of the family - The families were generally healthy and usually made few visits to doctors. One mother was receiving regular treatment for depression. Parental sleep was disrupted for a mean of 24 nights before admission (range 7-60), and for much of this time all parents were woken at least five times. Six mothers got up "constantly"- that is, 10-15 times a night-or sat up with their child all night. After discharge sleepless nights began again for 19 parents. At the second interview 10 said that their nights were fairly undisrupted while 11 were still getting up an average of three to four times. Sleeping arrangements, which had been extensively disrupted, were back to normal again in only 11 .

The child's stay in hospital was rated as a traumatic experience for 11 $(69 \%)$ fathers, $13(62 \%)$ mothers, and seven (54\%) sets of siblings. At the second interview three mothers thought that their marriage was better, four worse, and nine the same. Of the four whose marriages deteriorated, one husband walked out and one began to drink heavily. Neither of these marriages was rated as unhappy before the illness. Relatives helped to some extent in 15 families and friends in two, but five families had no help. Only four $(20 \%)$ siblings were thought to be unaffected. Tiredness ("too tired to do his homework") was the main problem, though seven also felt neglected or jealous and one developed a stutter. Family activity scores reduced considerably during the illness ( $<<0.0001$ for all relationships) (table IV), though this had largely resolved by the second interview.

TABLE IV-Scores for family activity on the check list. (Figures are totals (and means))

\begin{tabular}{lrrr}
\hline & $\begin{array}{c}\text { Before } \\
\text { illness }\end{array}$ & $\begin{array}{c}\text { Just before } \\
\text { admission }\end{array}$ & $\begin{array}{c}\text { At second } \\
\text { interview }\end{array}$ \\
\hline Child and mother $(\mathbf{n}=19)$ & $192(10 \cdot 1)$ & $127(6 \cdot 7)$ & $189(9 \cdot 9)$ \\
Child and father $(\mathbf{n}=15)$ & $120(8 \cdot 0)$ & $83(5 \cdot 5)$ & $119(7 \cdot 9)$ \\
Child and siblings $(n=13)$ & $91(7 \cdot 0)$ & $36 \cdot(2 \cdot 8)$ & $86(6 \cdot 6)$ \\
Mother and father $(\mathbf{n}=15)$ & $119(7 \cdot 9)$ & $52(3 \cdot 5)$ & $106(7 \cdot 1)$ \\
\hline
\end{tabular}

All mean scores before illness $v$ scores before admission, $\mathrm{p}<0.001$; all mean scores before illness $v$ second interview scores, NS (paired $t$ test).

Vaccination against whooping cough and parents' views-No child was fully vaccinated, and only one had been partially vaccinated. Thirteen mothers had not had or were intending not to have their child vaccinated, and for eight of these the main reason for this decision was the "brain damage scare." Several mothers had seen television programmes featuring children with brain damage, and two mothers knew children with brain damage (not due to vaccination against whooping cough) and found them distressing. Parents' knowledge of the risks of brain damage varied from "six in 100 " to a common statement of "so many in a thousand"; only one mother was able to quote the official estimate of about 1:300000. At the second interview 15 were of the same opinion about vaccination, and, although five changed their minds in favour of vaccination, seven would still not have a future child vaccinated, preferring to risk the possibility of the illness again.

\section{Discussion}

Previous studies have examined the effects on the family of chronic illnesses such as cystic fibrosis, ${ }^{8}$ leukaemia, ${ }^{9}$ and the nephrotic syndrome, ${ }^{10}$ but few have been concerned with acute illness and none with whooping cough. The children and families we studied did not appear to be unusual and had in general been previously healthy. The usual preponderance of girls was noted among the patients, ${ }^{11}$ and the proportion of cases in the manual classes $(67 \%)$ corresponded closely with the $64 \%$ in a larger, earlier study. ${ }^{5}$ Though only a small proportion of children with whooping cough is admitted to hospital ( $3 \%$ or less in the $1977-9$ epidemic ${ }^{12}{ }^{12}$ ), these children do not necessarily have more serious disease than those not admitted, as a substantial proportion of childhood admissions are partly or wholly for social reasons. ${ }^{13}$

Most children were very distressed by their illness; the child's behaviour clearly deteriorated during the illness before admission and had still not returned to normal by about two months later. The stay in hospital itself may have played a part in this ${ }^{1416}$ and may have had later consequences. ${ }^{17-18}$ Nevertheless, data acquired at the first interview were unlikely to have been influenced by the stay in hospital, and events such as parental loss of sleep were clearly specific to the illness.

The illness proved to be a tremendous strain on most families, as previously noted in a community study. ' Almost all families in our study had prolonged problems of a temporary nature such as extensive disturbance of sleep, but in general, despite considerable disruption during the illness, the families seemed largely to have returned to normal by the second interview. The possibility of a long lasting effect on siblings, however, needs to be studied more carefully, and in certain families there were longer term problems such as break up of the marriage.

Although the duration of an illness such as whooping cough is difficult to define, mothers had little doubt that there was a point at which their child ceased to be ill and began to improve, and another, perhaps less well defined, point at which the child was back to normal. The duration of illness found here confirms the estimate of the Department of Health and Social Security of 10-12 weeks, ${ }^{19}$ though over a quarter had an illness lasting 16 weeks or more. One 
of the most disturbing times for many parents was after discharge, when they were again faced with repeated coughing and vomiting after the relief afforded by the child's admission to hospital.

Parents had little prior knowledge of whooping cough, and $81 \%$ found it more serious than they had imagined. Television programmes about the disease had given little idea of its potential severity. Almost all mothers had been worried that their child might die, though later the major fear was the possibility of permanent chest trouble. These worries need to be explored with parents during the child's admission, and one function of follow up should be to reassure parents about the likely outcome. Parental opinion about vaccination underlines both the power and the weakness of the media. ${ }^{20}$ Almost all knew about the "brain damage scare," yet only one was able to give a reasonably accurate estimate of the incidence of brain damage.

Finally, the experiences of parents in contact with health services ranged from very satisfactory to execrable. Problems arose both in general practice and in hospitals from doctors' ignorance about the illness; their comments, such as "too young to have whooping cough"; their unwillingness to accept the mother's account of the child's illness or consider the diagnosis; and sometimes their apparent ignorance of the availability of medical skill. Whooping cough may certainly be difficult to diagnose. The child often appears deceptively well between spasms, but in this study mothers' clearcut histories were often disregarded. Two thirds of mothers had been sure that their child had whooping cough, often despite medical denials, and there was often great relief when the diagnosis was finally confirmed, a reaction noted previously in the context of other childhood illnesses. ${ }^{21} 22$

We thank the Department of Health and Social Security for supporting the work.

\section{References}

1 Royal College of General Practitioners. Report from the Swansea research unit. Br Med 1981;282:23-6.

2 Pollock TM, Miller E, Lobb J. Severity of whooping cough in England before and after the decline in pertussis immunisation. Arch Dis Child 1984;59:162-5.

3 Walker E Pinkerton IW, Love WC Chaudhuri AKR, Datta JB Whooping cough in Glasgow 1969-80. F Infect 1981;3:150-8.

4 Robinson DA, Mandal BK, Ironside AG, Dunbar EM. Whooping cough-a study of severity in hospital cases. Arch Dis Child 1981;56:687-91.

5 Johnston IDA, Anderson HR, Lambert HP, Patel S. Respiratory morbidity and lung function after whooping cough. Lancet 1983 ;ii:1104-8.

6 Graham P, Rutter $M$. The reliability and validity of the psychiatric assessment of the child. II Interview with the parent. Brf Psychiatry 1968;114:581-92.

7 Jenkins S, Bax M, Hart H. Behaviour problems in pre-school children. 7 Child Psychol Psychiatr $1980 ; 21: 5-17$

8 Gayton WF, Friedman SB, Tavormina JF, Tucker F. Children with cystic fibrosis. Psychological test findings of patients siblings and parents. Pediatrics 1977;59:888-94.

9 Binger CM, Ablin AR, Feuerstein RC, Kushner JH, Zoger S, Mikkelsen C. Childhood leukemia Emotional impact on patient and family. N Engl f Med 1969;280:414-8.

10 Vance JC, Fazan LE, Satterwhite B, Pless IB. Effects of nephrotic syndrome on the family: a controlled study. Pediatrics 1980;65:948-55.

11 Christie AB. Infectious diseases: epidemiology and practice. Edinburgh: Churchill Livingstone, 1980.

12 Grob PR, Crowder MJ, Robbins JF. Effects of vaccination on severity and dissemination of whooping cough. Br Med f 1981;282:1925-8.

13 Wynne J, Hull D. Why are children admitted to hospital? BrMed f 1977;ii:1140-2.

14 Prugh DG, Staub EM, Sands HH, Kirschbaum RM, Lenihan EA. A study of the emotional reactions of children and families to hospitalisation and illness. Am f Orthopsychiatr 1953:23:70-106.

15 Vernon DTA, Schulman JL, Foley JM. Changes in children's behaviour after hospitalisation. Am f Dis Child 1966;111:581-93.

16 Brain DJ, Maclay I. Controlled study of mothers and children in hospital. BrMed f 1968;i:278-80.

17 Douglas JWB Early hospital admissions and later disturbances of behaviour and learning. Deo Med Child Neurol 1975:17:456-80

18 Quinton D, Rutter M. Early hospital admissions and later disturbances of behaviour. Dev Med Child Neurol 1976;18:447-59.

19 Department of Health and Social Security. Whooping cough: reports from the Committee on Safety of Medicines and the foint Committee on Vaccination and Immunisation. London: HMSO, 1981

20 Church MA. Return of whooping cough. Br Med f 1979;i: 195

21 Lansdown R. More than sympathy. The evervday needs of sick and handicapped children and their families. London: Tavistock Publications, 1980.

22 Burton L. The family life of sick children. London: Routledge and Kegan Paul, 1975.

(Accepted 21 January 1985)

\title{
Should all casualty radiographs be reviewed?
}

\author{
J WARDROPE, P M CHENNELLS
}

\begin{abstract}
The effect on the management of patients of routine reporting of casualty radiographs by radiologists was reviewed. The overall prevalence of error by casualty doctors was $6 \cdot 2 \%$. Many of these errors, however, were trivial and did not alter treatment. In only $1.1 \%$ of the cases reviewed did the report of $x$ ray films appreciably alter the management of the patient. A severity score was introduced to highlight those anatomical areas in which important lesions were overlooked most often. Radiologists'
\end{abstract}

\footnotetext{
Departments of Accident and Emergency and Diagnostic Radiology, General Infirmary, Leeds LS1 3EX

J WARDROPE, MB, FRCS, research registrar

P M CHENNELLS, MB, FRCR, consultant radiologist
}

Correspondence to: Mr J Wardrope, Accident and Emergency Department, Royal Hallamshire Hospital, Sheffield S10 2JF. reports on radiographs of the chest, face, skull, and wrist had the greatest effect on management of patients, while reports on radiographs of fingers, hands, shoulders, long bones, and toes seldom altered treatment.

\section{Introduction}

Casualty officers interpret casualty radiographs reasonably accurately. ${ }^{12}$ Some errors have little influence on the management of patients as the treatment is based on clinical assessment. Other errors, however, may have serious consequences, and it has been recommended that all casualty radiographs be reported by a radiologist.' The increasing workload presented to the accident department imposes a large burden on the radiologist, who may have to report many radiographs to identify one important error.

We undertook a survey to identify which errors had the greatest effect on management of patients and to ascertain whether any anatomical areas could be excluded from routine reporting. 